Psicologia \& Sociedade; 14 (1): 69-86; jan./jun.2002

\title{
O BRASILEIRO, O RACISMO SILENCIOSO E A EMANCIPAÇÃO DO AFRO-DESCENDENTE
}

Ricardo Franklin Ferreira Universidade de São Marcos

RESUMO: Este ensaio descreve alguns acontecimentos que revelam formas pelas quais o preconceito é veiculado. Em seguida, teço comentários acerca de algumas condições históricas para o desenvolvimento do preconceito. Ressalto, na análise, o projeto epistemológico da modernidade que, apoiando-se num pensamento metafísico, voltou-se para a busca de certezas, desenvolvendo horror à ambivalência, determinando uma busca obsessiva pela classificação e a ordem. Considero este um terreno fértil para a constituição de subjetividades voltadas para a exclusão do diferente e, em decorrência, para o desenvolvimento de estereótipos negativos acerca da população negra, que subsistem até hoje, além de situações concretas de desqualificação social desses brasileiros. Tais processos tendem a ampliar ainda mais os contrastes econômicos e sociais, situações incompatíveis com o país que desejamos construir. Na seqüência ressalto um processo favorecedor do desenvolvimento de uma identidade afrocentrada, uma das condições para a reversão do preconceito.

PALAVRAS-CHAVE: afro-descendente, identidade, preconceito, família, modernidade

\section{THE BRASILIAN, THE SILENT RACISM AND THE AFRO DESCENDANT EMANCIPATION}

ABSTRACT: This essay describes some incidents that disclose how prejudice is transmitted. After that, I argument about some historic conditions that promote the expansion of prejudice. I stand out the epistemological project of Modernity which, supported in a metaphysical thought, looked for certainties, developed horror to ambivalence and determined a obsessive search for classification and order. I consider this a fertile field to the constitution of subjectivities that exclude the different. So, this process develops stereotypes about black people, besides real situations of social disqualification of this Brazilians. These processes tend 
Ferreira, R.F. "O brasileiro, o racismo silencioso e a emancipação do afro-descendente"

to amplify the economics and social contrasts much more. These are incompatible occurrences in a country that we whish to construct. Finally, I emphasize a favorable process to the development of an afro-centered identity, one of many conditions to the prejudice reversion.

KEY WORDS: Afro-descendant, identity, prejudice, family, Modernity

\section{PRECONCEITO: ATRIBUTO DO ‘OUTRO’?}

"Não caçamos pretos, no meio da rua, a pauladas, como nos Estados Unidos. Mas fazemos o que talvez seja pior. A vida do preto brasileiro é toda tecida de humilhações. Nós tratamos com uma cordialidade que é o disfarce pusilânime de um desprezo que fermenta em nós, dia e noite"

\section{Nelson Rodrigues}

Nelson Rodrigues, 'especialista' em denunciar aquilo que geralmente se esconde por detrás das aparências, aponta uma farsa da qual, muitas vezes, o brasileiro se orgulha - a crença de que, no Brasil, vive-se uma 'democracia racial'. O preconceito contra a população negra, em função de um mito que o nega, torna-se difícil de ser compreendido e combatido. Há mecanismos subliminares de encobertamento permeados por um aparente tratamento cordial, desenvolvendo a crença de que a discriminação etnoracial não existe, como já discuti em trabalhos anteriores (Ferreira, 1999a, 2000).

Assim, 'não temos de compreender o que não existe'.

Sabe-se da discriminação, mas não se quer falar a respeito. Diversas pesquisas, como as apontadas pela Revista Veja (10.01.1996) e pela Datafolha (Rodrigues, 1995), foram unânimes em ressaltar que o preconceito é sistematicamente considerado como atributo do "outro". Os resultados da pesquisa Datafolha apontam que $89 \%$ dos brasileiros afirmam saber existir preconceito contra os brasileiros negros, mas somente $10 \%$ o admitem como seu. Schwarcz (1996) chegou a resultados mais extremos - 97\% das pessoas afirmaram não ter preconceito e $98 \%$ dos entrevistados diziam conhecer, sim, amigos e parentes próximos que têm preconceito racial. 
Portanto, têm-se consciência do racismo ${ }^{1}$, porém, considera-se como um problema do outro.

Assim, no Brasil, o preconceito não é abertamente afirmado, dificultando a elaboração de leis que favoreçam sua reversão. A ideologia de que vivemos num país em que as diferenças são aceitas e valorizadas, 'um verdadeiro exemplo para as outras nações', encobre o problema. Em função disso, a população negra encontra-se submetida a um processo em que as condições de existência e o exercício de cidadania tornam-se muito mais precários com relação à população considerada branca. Em decorrência, a construção de uma identidade positivamente afirmada, requisito necessário para as pessoas se engajarem em políticas efetivas voltadas para a melhoria de suas condições sociais, torna-se um processo dificultado.

Tendo em vista tais referências, busquei, neste ensaio, ampliar a compreensão sobre alguns processos envolvidos na construção da identidade do brasileiro afro-descendente. Para isso, parti de algumas experiências vividas por três mulheres de uma família negra (Ferreira, 2002).

\section{O PRECONCEITO SILENCIADO}

A família composta pelo casal Neusa e João, as filhas Sandra, 21 anos, Rosa, 19 anos, e José, o filho de 16 anos, apresenta uma configuração muito comum, no caso brasileiro, no que se refere à categoria raça ${ }^{2}$, pois as pessoas se posicionam em 'lugares' diversos dentro de um gradiente étnico de cor. Conforme as percepções dessas pessoas, o pai e o irmão sempre foram considerados negros; Neusa, era considerada branca e hoje, negra; Rosa, via-se como morena e a irmã Sandra, como mulata, e hoje ambas definem-se como negras. Pode-se observar que, além da diversidade de atribuições em relação à cor, há também mudanças nas autoatribuições em função de experiências vividas. A partir de episódios de discriminação racial sofridos, de participações em grupos de militância e movimentos culturais, como o rap, por exemplo, todos passaram a considerar-se negros, independente da tonalidade de pele ser mais clara ou mais escura. Esse processo será melhor compreendido a partir do item 4.

$\mathrm{Na}$ família em questão, quando os filhos eram crianças, não se falava sobre questões raciais e experiências de preconceito e, quando eram discutidas, isto se dava de maneira jocosa. Consideravam tais questões como insignificantes.

Tais depoimentos revelam o que foi bem analisado por Cavalleiro (1998): de que nos lares de famílias negras e na escola, a maneira mais 
Ferreira, R.F. "O brasileiro, o racismo silencioso e a emancipação do afro-descendente"

comum de se lidar com o preconceito é o silêncio. Nessa família, o termo 'moreno' era usado para se auto-referirem a características etnoraciais, eufemismo comum e que nega as características fenotípicas.

Parece ser 'politicamente correto' tratar o afro-descendente como 'moreno', palavra fortemente enraizada na cultura brasileira. É um exemplo de uma situação que revela uma estratégia simbólica de fuga de uma realidade em que a discriminação impera. Dessa forma, as pessoas procuram elementos de identificação em símbolos do grupo considerado social e economicamente dominante, no caso o brasileiro branco-europeu.

Tais questões sugerem a dificuldade de se lidar, no Brasil, com o preconceito racial. Este revela-se no dia-a-dia, nas situações mais simples. Numa sociedade em que, apesar da crença consolidada de ser o país da democracia racial, as pessoas desenvolvem um mundo simbólico, cujas características fenotípicas acabam operando como referências para o preconceito. No caso do afro-descendente, este processo torna-se dramático, pois é veiculado e, muitas vezes, encoberto por 'frases educadas', alimentando o mito brasileiro de estarmos vivendo num paraíso de coexistência e de aceitação das singularidades. Tal visão conserva o problema, pois este deixa de ser enfrentado em função da idéia de ele não existir.

Se assumirmos que as interações sociais são processos constitutivos das identidades pessoais, situações como a da família que silencia acerca de suas características etnoraciais podem favorecer a introjeção de valores negativos de uma forma tácita, não só por parte da pessoa que se coloca no 'outro grupo' mas, o que é mais dramático, pelo próprio afro-descendente em relação a si mesmo. Identidades assim constituídas conservam a incapacidade de desenvolver atitudes afirmativas quanto às especificidades raciais.

Gostaria de enfatizar aspectos que considero importantes acerca de algumas condições históricas que favoreceram a instalação do preconceito.

\section{O PRECONCEITO RACIAL E A HERANÇA MODERNA}

Em torno do século XIV, o homem ocidental lançou-se no mundo, transpondo fronteiras e limites que até então lhe davam segurança. Foi o período das grandes navegações - novos lugares, novos idiomas, novos costumes, enfim, novas concepções de realidade. Deparou-se com um universo de extrema diversidade. Momento de espanto, a partir do qual as tradições já não se mostravam suficientes para que o homem se organizas- 
se de maneira segura em sua realidade, levando-o à tarefa de reconstrução de novas crenças e regras de ação seguras e confiáveis. Através do uso da consciência reflexiva, desenvolveu ao máximo os procedimentos de controle sobre os acontecimentos. Para Bauman (1999), uma estratégia tipicamente moderna, pois o pensamento moderno não suporta a ambivalência e as coisas fora de ordem. "Ordem e caos são gêmeos modernos. Foram concebidos em meio à ruptura e colapso do mundo ordenado de modo divino, que não conhecia a necessidade nem o acaso, um mundo que apenas era, sem pensar jamais em como ser" (p. 12).

E a busca da ordem constituiu-se, não como mero processo de representação do real, mas como dispositivo de instalação do humano, através de uma estratégia preferencial - a de classificar. Tal processo, analisado com muita pertinência por Bauman (1999), nos direciona a uma das chaves de compreensão da construção da subjetividade do homem moderno. O processo de classificar, obsessão da civilização ocidental, constituiu-se nos atos de incluir o semelhante num padrão considerado desejável e correto, excluindo o diferente. Cada ato de classificação compreende a divisão do mundo em dois: entidades que respondem a um conceito e todo o resto que se diferencia dele. Mais que isso, “...tal operação de inclusão/ exclusão é um ato de violência perpetrado contra o mundo e requer o suporte de uma certa dose de coerção" (p. 11). Assim, as figuras do 'outro' da ordem são: "a indefinibilidade, a incoerência, a incongruência, a incompatibilidade, a ambigüidade, a confusão, a incapacidade de decidir, a ambivalência - ... pura negatividade" (p. 14-15). O outro passa a constituirse na fonte e arquétipo de todo o medo.

Como resultante, a intolerância passa a constituir-se como atitude básica, decorrente das práticas desenvolvidas na modernidade - terreno fértil para a construção de subjetividades prontas para a desligitimação do outro, daquele considerado divergente dos padrões assumidos como verdadeiros e bons.

Acreditava-se que tais processos permitiriam o alcance da ordem e esta, por sua vez, a previsão e controle de fenômenos da natureza, procedimentos voltados para o desenvolvimento de uma civilização melhor, através do progresso.

Ordem e progresso, lema conhecido nosso.

Ordem e progresso, condições legitimadoras da transformação do outro no 'mesmo'. Para o africano escravizado, convertê-lo ao cristianismo, apagar sua história ou, o que conhecemos muito bem, através de um processo de branqueamento e aculturação, torná-los 'brancos', como no 
Ferreira, R.F. "O brasileiro, o racismo silencioso e a emancipação do afro-descendente"

caso de Sandra, a mulher negra que se considerava branca. Numa outra alternativa, se houver resistência, a exclusão, a expulsão para 'fora'.

Como analisa Bauman (1999), "libertando das restrições morais a ação com um propósito, a modernidade tornou o genocídio possível" (p. 58). Sem considerá-lo como uma causa suficiente, ele atribui à modernidade a condição necessária para a sua ocorrência. Compreende as concepções desenvolvidas na modernidade como condições determinantes para a ocorrência do holocausto judaico, um genocídio de extrema visibilidade.

Quero, aqui, sugerir que tais concepções, enraizadas na busca da ordem e na eliminação da ambivalência, serviram, da mesma maneira, de terreno para a realização de um genocídio mais silencioso, mais gradual, mais lento - aquele que se deu contra a população africana escravizada. A experiência da escravidão no Brasil transformou o africano em escravo, $\mathrm{o}$ escravo em negro, e o negro numa pessoa destinada a 'desaparecer', em nome da constituição de um povo cordial e moreno.

Nessa direção, a idéia do branqueamento foi defendida, no início do século XX, por vários cientistas e representantes da intelectualidade brasileira, sem esquecer que na modernidade os representantes da ciência passaram a ser os legitimadores das 'verdades' estabelecidas.

Os trabalhos de Schwarcz (1998) e Consorte (1999) analisam com muita propriedade esse período. Havia justificativas, consideradas científicas, que legitimavam o eurocentrismo ${ }^{3}$, favorecendo políticas de branqueamento que, para Larkin Nascimento (2000), apoiavam-se em duas condições básicas: "a imigração européia em massa, subsidiada pelo Estado, sob legislação que excluía raças não desejáveis; e o cultivo do ideal do embranquecimento" (p. 117).

Vejamos alguns exemplos. Em 1911, no I Congresso Internacional das Raças, João Batista Lacerda apresentou uma tese que previa a extinção dos mestiços e pessoas de raça negra, na entrada do novo século (Schwarcz, 1998). Nessa mesma direção, o antropólogo Roquete Pinto, em 1927, no Congresso Brasileiro de Eugenia, fazia sua previsão de que em 2012, a população brasileira seria constituída por $80 \%$ de brancos e $20 \%$ de mestiços, nenhum negro e nenhum índio. O psiquiatra Nina Rodrigues, pioneiro nos estudos científicos da população afro-descendente brasileira, estudou a origem, a cultura, a religião e a influência dos africanos e seus descendentes na Bahia, embora defendesse teses racistas. Adepto do darwinismo racial, no começo do século, talvez tenha sido quem proclamou com maior ênfase a inferioridade do negro e a degenerescência do mestiço - a raça negra no Brasil "há de se constituir sempre um dos fatores 
da nossa inferioridade como povo" (Nina Rodrigues, 1977, p. 28).

Estou querendo apontar três condições favoráveis ao desenvolvimento do preconceito e sua forma de expressão no Brasil: (a) uma concepção constitutiva das subjetividades ocidentais, desenvolvida na modernidade, que busca ordem, desvalorizando ou eliminando o 'diferente'; (b) um processo histórico, legitimado por tal concepção, que levou à escravidão do africano e redução de sua condição a mero objeto de uso; (c) posteriormente, já após a Abolição, o desenvolvimento de concepções, apoiadas pela ciência, acerca da inferioridade racial do negro, a ponto de se 'prever' sua extinção na constituição do povo brasileiro.

Num contra-movimento, nos anos 30, o mestiço passa a ser louvado como símbolo de nossa identidade. Primeiro a desvalorização, depois a exaltação. Assim, foi sendo gestado um mito que passou a constituir o pensamento brasileiro - o mito da 'democracia racial', formulado de maneira exemplar por Gilberto Freyre.

Temos aqui o fértil terreno para a constituição do racismo silencioso, o peculiar racismo à brasileira - uma visão negativa do afro-descendente e um discurso contrário que tenta negá-la. Assim, está constituído o espinhoso terreno no qual é gestada a identidade do brasileiro afro-descendente.

\section{UMA IDENTIDADE REFERENCIADA NO MUNDO BRANCO}

Em função do processo de desvalorização da pessoa negra, os afrodescendentes tendem a introjetar a visão dominante de mundo branco, visto como superior. Em decorrência, tendem a desvalorizar o mundo negro ou assumirem como insignificante para suas vidas o fato de serem afrodescendentes, como na família que mencionei.

Há uma série de situações favoráveis à sustentação das distorções a respeito das matrizes negras, dentre elas, a educação formal. Para Pereira (1987), a escola é um lugar onde a criança alimenta subliminarmente a figura do 'negro caricatural'. No plano do relacionamentos, a instituição escolar reproduz naquele microcosmo a mesma estrutura de relação que se dá na sociedade brasileira como um todo (Miranda, 1989). Assim, a escola, em vez de ser um lugar de reversão do problema, estimula os estereótipos sociais relativos a essa população e a submissão do afro-descendente aos valores brancos, o que foi bem analisado por Cavalleiro (1998) e Camargo (2001). Apoiando-se numa visão de mundo histórico-cultural eurocêntrica, cria um processo pedagógico tal que leva o afro-descenden- 
Ferreira, R.F. "O brasileiro, o racismo silencioso e a emancipação do afro-descendente"

te a inibir sua capacidade de advogar seus interesses culturais, políticos e econômicos aos quais tem direito como cidadão. Sua história é interpretada de maneira distorcida. É muito comum os problemas etnoraciais serem considerados sob o prisma da 'culpabilidade da vítima', isto é, que as condições sociais e econômicas precárias são fruto da inépcia e falta de capacidade pessoal dos indivíduos afro-descendentes.

As noções de beleza são derivadas de uma estética 'branca', usada como 'referência correta', positiva, racional e bem desenvolvida, levando, em decorrência, a uma desvalorização da estética negra, encarada como exótica, emocional e primitiva, qualidades consideradas 'menores'. Como exemplo, aponto duas experiências relatadas por Rosa, em relação à cor de pele, e de Sandra, em relação ao seu cabelo:

$\mathrm{Na}$ época em que eu comecei a tomar banho sozinha... eu me esfregava muito porque eu achava que era sujeira... que eu não podia ser assim, uma das mais escurinhas da minha sala... que era sujeira mesmo... (Rosa)

Eu comecei a lembrar... (chorando) de uma época em que eu estava na escola... em que eu comecei a viver muito forte o preconceito... Eu lembro que era por causa do meu cabelo... foi uma época em que uma amiga alisou o meu cabelo e... nossa... fui ridicularizada (chorando)... meus amigos... meu namoradinho da época... a minha melhor amiga... (Sandra)

Assim, Rosa e Sandra buscavam se aproximar ao máximo das características das pessoas consideradas brancas.

Evidências empíricas, como as de Parham \& Helms (1985), sugerem que as pessoas submetidas à discriminação tendem a apresentar autoconceito pobre, baixa auto-estima, auto-realização pobre, ansiedade e depressão. $O$ indivíduo, tem a sensação de não se 'encaixar' realmente em nenhum grupo, pois internaliza os valores 'brancos' e é desqualificado por ser negro, de tal forma que passa a desvalorizar-se como pessoa. Para Souza (1983), o negro vive uma dramática insatisfação, independente de seus êxitos, pois nunca alcançará o ideal de ego branco.

Entretanto, se ele gradualmente tomar consciência da desvalorização à qual está submetido, pode iniciar um movimento na direção de uma transformação, vindo a valorizar-se por suas características etnoraciais. 
Psicologia \& Sociedade; 14 (1): 69-86; jan./jun.2002

\section{TORNAR-SE NEGRO}

Experiências desconfirmatórias, gradualmente, podem provocar transformações. São processos conflitivos, pois questionam a maneira de ser e de ver o mundo e tornam impossível ao negro negar a rejeição que sofre socialmente. São experiências que destroem a funcionalidade da visão de mundo presente e, ao mesmo tempo, sugerem nova direção no sentido de uma transformação ou ressocialização.

Numa sociedade onde há discriminação, como a brasileira, é claro ter a pessoa afro-descendente já se deparado, por diversas vezes, com situações de afronta e indignidade em função de suas características etnoraciais, sob a forma de agressões físicas ou verbais abertas, ou através de formas mais sutis, como recusas com relação a empregos sob diferentes justificativas. É comum o negro ser pessoalmente agredido na escola ou na situação de trabalho, ser rejeitado para uma festa ou ser testemunha da agressão sofrida por um amigo.

Neste sentido, o depoimento de Sandra é esclarecedor:

Um dia, teve uma festa de aniversário... Quando nós chegamos na festa, ficamos do lado de fora esperando ele aparecer (o anfitrião)... Ele veio, cumprimentou a Rosa... e... nada de vir falar com a gente... o pai dele na porta da garagem... olhando muito feio pra todo mundo... olhando muito feio pra mim, pro meu irmão, pro pessoal que estava com a gente... até que a Rosa veio e comentou... ela estava quase chorando... estava muito mal... falou que o pai dele tinha reclamado desses amigos estranhos que estavam lá. Então... esses amigos estranhos... foi mais ou menos como dizer 'esses seus amigos negros... eles vão roubar, eles vão fazer alguma coisa'... E aí, nós viemos embora da festa (Sandra).

Como este fato, a sucessão de pequenos episódios vividos pela pessoa cria um efeito cumulativo, levando-a cada vez mais a tomar consciência de que é sistematicamente rejeitada e vista com menos valia. Deparando-se com tal realidade, passa a focalizar-se em aspectos de sua identidade que a inclui no grupo discriminado, o dos afro-descendentes.

Além das situações de rejeição, mudanças podem ocorrer a partir da exposição a eventos que envolvem informações relevantes acerca de aspectos culturais e históricos da experiência negra. À medida que assimi- 
Ferreira, R.F. "O brasileiro, o racismo silencioso e a emancipação do afro-descendente"

la essas novas informações e passa a usá-las como referências pessoais, o sujeito é desafiado a repensar de maneira radical suas concepções sobre as questões negras. Este momento contém uma faceta dolorosa, pois é inevitável ao indivíduo sofrer a desarticulação de seu mundo simbólico.

É uma experiência aflitiva, pois a pessoa descobre que seus valores e sua visão de mundo não permitem mais um posicionar-se seguro na realidade. Entretanto, como nos aponta Cross (1991), são reações temporárias pois ela, gradual e cuidadosamente, vai aprendendo a testar a validade de suas novas percepções. A grande gama de emoções com a qual vê-se envolvida poderá, entretanto, transformar-se em fatores favoráveis, por gerarem grande energia para a ação. Ela tende a dirigir sua revolta ao que atribui como a 'causa' dos problemas sofridos anteriormente, ou seja, as pessoas brancas. É um momento delicado, no qual o afro-descendente poderá praticar o preconceito em via inversa.

Após o período de conflito, no qual o afro-descendente sente desorganizar sua estrutura de subjetividade referenciada em valores 'brancos', antes provedora de sustentação e segurança, inicia-se um processo de intensa metamorfose pessoal em que ele, gradualmente, vai demolindo velhas perspectivas e, ao mesmo tempo, passa a desenvolver uma nova estrutura pessoal referenciada em valores etnoraciais de matrizes africanas.

Em seu trabalho, Helms (1993) pontua ter estado a pessoa, até esse momento, submetida a uma visão do negro determinada pela cultura branca e sua maneira de agir ainda é estereotipada, sendo a referência da pessoa negra uma referência de grupo definida externamente, levando-a a pensar, sentir e comportar-se de acordo com padrões idealizados de como a pessoa negra 'deve' agir.

É provável que tal situação explique porque é comum o afro-descendente apegar-se de forma obsessiva a símbolos da nova identidade em processo de construção, a jargões verbais, a algumas ideologias rígidas e a avaliações dicotômicas de mundo, semelhantes ao que discuti acerca de uma subjetividade desenvolvida na modernidade (ítem 3). Há a tendência de considerar todos os brancos como 'maus' e desumanos e os negros como superiores, mesmo no sentido biogenético, passando a presença de melanina na pele a ser vista como um sinal de superioridade racial.

A pessoa mergulha no mundo negro. Passa a participar de grupos onde seus valores são intensamente afirmados. O grupo apóia o novo "convertido', valorizando novos códigos, roupas, comportamentos, além de favorecer um padrão de conformidade por parte do novo militante. Há um envolvimento em organizações voltadas para a busca de estratégias de com- 
Psicologia \& Sociedade; 14 (1): 69-86; jan./jun.2002

bate à discriminação racial e movimentos de valorização da cultura negra. Quaisquer conteúdos africanos tornam-se valorizados e os interesses são intensamente voltados a eles. É freqüente, nessa experiência de mergulho, a pessoa vivenciar um desenraizamento, acompanhado de sentimentos de raiva contra a cultura e pessoas brancas, ocorrendo uma situação paradoxal: para fugir ao conformismo a uma cultura que valoriza a pessoa branca e inferioriza o negro, o indivíduo pode cair num outro tipo de conformismo - o do novo grupo etnoracial de referência. Nessa situação, os indivíduos apresentam uma subjetividade construída em torno, principalmente, da aversão e negação dos valores brancos, portanto ainda não numa perspectiva de afirmação positiva de suas referências negras.

É importante uma análise mais aprofundada dos grupos de militância negra, no sentido de criar mecanismos que evitem o problema apontado por Figueiredo (1995), num ensaio onde são analisados aspectos da identidade das pessoas que participam da militância como um modo de vida. Ele ressalta que o militante tende a desenvolver uma identidade apoiada em procedimentos de exclusão e vedamento que resultam na "repetição estéril do próprio terreno que pretendia transformar" (p.114), independentemente do contexto - político, religioso, científico, - e da direção - 'revolucionária', 'conservadora' ou 'alternativa' - em que a militância esteja sendo exercida. Tratando-se do desenvolvimento de uma identidade articulada em torno de características etnoraciais, o fechamento em torno de suas novas referências pode alimentar uma atitude preconceituosa, agora contra o euro-descendente, preservando exatamente o mesmo padrão de subjetividade que o militante visa transformar.

Creio que, apesar dos problemas apontados acima, considero ser importante a participação do afro-descendente em grupos de movimento negro, pois o militante tem a chance de recuperar os valores da cultura e da história africana. Através de um processo de reconstrução, pode revisar os valores introjetados e os estereótipos negativos assimilados durante o processo de socialização, o que vem favorecer, assim, uma auto-estima mais positiva e relacionamentos harmoniosos no âmbito sócio-cultural mais amplo. Estes aspectos são concordantes com os resultados de uma pesquisa realizada no Brasil por Souza (1991).

Gradualmente, o afro-descendente tende a abandonar as ideologias simplificadoras, freqüentemente reconhecendo suas primeiras impressões sobre a negritude, como românticas e idealizadas. Há certa decepção com relação aos grupos radicais, passando a participar de grupos mais seriamente voltados para uma reversão da discriminação e valorização das 
Ferreira, R.F. "O brasileiro, o racismo silencioso e a emancipação do afro-descendente"

matrizes africanas

Aos poucos, a pessoa pode passar a ter atitudes mais abertas e menos defensivas, voltadas para a valorização das matrizes africanas. $\mathrm{O}$ grupo negro torna-se o principal grupo de referência, sendo seu vínculo determinado por qualidades do próprio grupo e, não mais, exclusivamente, por fatores externos a ele (Helms, 1993). Para Cross (1991), a 'nova identidade' construída tem três funções dinâmicas: defender e proteger a pessoa de agressões psicológicas; prover um sentido de pertença e ancoradouro social e prover uma fundação, ou ponto de partida, para transações com pessoas de culturas diferentes daquelas referenciadas em matrizes africanas. $\mathrm{O}$ indivíduo, além de manter relações com pares negros, estabelece relacionamentos significativos com não negros no seu convívio, respeitando suas auto-definições. Deverá estar pronto, também, para realizar coalizões com membros de outros grupos organizados em torno de projetos ou valores distintos, deixando de referenciar-se no preconceito como um universo por si só. A referência raça e a cultura africana, antes vistas como de pouca importância, tornam-se fundamentais para a vida diária. $\mathrm{O}$ afro-descendente passa a sentir-se aceito, com propósito de vida, sentindo-se profundamente enraizado na cultura negra, sem deixar de perceber as condições às quais está submetido num mundo que o vê com preconceito. As matrizes africanas passam a ser efetivamente afirmadas. Torna-se negro. Como disse Sandra: "hoje eu tenho certeza que sou negra..., não tinha mais como lutar contra isso e achar que não éramos negras... eu acho que não nasci negra. Eu me tornei negra”.

\section{NÃO SOMOS MORENOS, SOMOS 'CRILOUROS'}

Creio que já podemos refletir acerca de algumas questões que a experiência das três mulheres da família entrevistada sugeriram, à luz do modelo que apresentei.

Houve, no Brasil, um processo histórico, articulado no projeto da modernidade, apoiado cientificamente, que, em busca da ordem e do progresso, criou mecanismos de deslegitimação do africano escravizado. Tal terreno criou condições favoráveis ao preconceito racial contra os afrodescendentes. Simultaneamente, a crença na 'democracia racial' aponta um discurso que nega esse fato. Porém, nos gestos, ele é veiculado de uma maneira sutil. Como nos alerta Lévinas (1997), não há gesto neutro. Todo gesto deixa vestígios e estes marcam o mundo, mesmo que deles não tenhamos consciência. Um dos vestígios constituiu-se em condições con- 
Psicologia \& Sociedade; 14 (1): 69-86; jan./jun.2002

cretas de menos valia para um grupo que perfaz quase metade da população.

Assim, estamos submetidos a dois discursos ambivalentes - um que expressa o preconceito e outro que o nega. Uma maneira de lidar com tal ambivalência parece ser o uso de uma estratégia simbólica de fuga pontuada por Rodrigues (1995) e Schwarcs (1996) - considerar o preconceito como atributo do 'outro', ou como aquela apontada por Sandra - 'considerar-se morena'. Apesar de tais mecanismos, o preconceito é efetivamente afirmado. Estas são condições favoráveis para o desenvolvimento de identidades articuladas em valores do 'mundo branco', considerados como superiores, tanto pela população negra como por parte da população branca.

Os fatos relatados também sugerem a possibilidade de uma reversão desse processo - o afro-descendente pode desenvolver uma subjetividade em que as características fenotípicas e os valores de raízes africanas possam ser vistos como positivos, além de apresentar atitudes mais afirmativas frente a situações de discriminação. É como diz Sandra: 'não se nasce negro, torna-se negro'.

Como a discriminação tende a ser um processo 'camuflado', não se tem abertura para que tais questões sejam discutidas, dificultando o processo de reversão do preconceito.

Entretanto, creio que já temos caminhado, atualmente, numa direção mais favorável a uma diminuição de atitudes preconceituosas, apesar de tratar-se de um processo lento.

O projeto da modernidade já vem sendo questionado e têm sido apontados novos paradigmas epistemológicos constituintes das subjetividades contemporâneas (Santos, 1996; Bauman, 1999; Morin, 1995).

Cabe aqui a proposta de um amplo debate, em termos educacionais, sobre o preconceito, as práticas discriminatórias e maneiras de superálos, pois a escola é um núcleo estruturante formador de futuros adultos. Além disso, creio ser uma importante contribuição a educação formal enfatizar as nossas raízes nos currículos e reconstruir a história do processo de formação do povo brasileiro, não mais sob a ótica branca oficial, mas com uma visão mais abrangente.

A participação em grupos de militância, sejam eles voltados para valores religiosos, como o Candomblé, com objetivos políticos ou culturais, pode favorecer um processo de reconstrução pessoal junto a interlocutores que vivem a mesma problemática, através do exercício de revisão dos padrões negativos introjetados e da possibilidade de contato com dados da história omitida. A militância é um espaço onde a vergonha 
Ferreira, R.F. "O brasileiro, o racismo silencioso e a emancipação do afro-descendente"

de ser negro pode transformar-se em orgulho de ser negro, onde o indivíduo passa a ter nova história, além de intensificar a luta, que já vinha desenvolvendo desde o início da escravidão, por sua afirmação, agora com companheiros articulados em âmbito mundial, na área governamental, na nãogovernamental e na academia. Com a recuperação da história da diáspora e das matrizes culturais africanas, também parte do cadinho cultural brasileiro, e com as reivindicações políticas e sociais, o afro-descendente pode dar visibilidade a qualidades que o branco não tinha se dado conta, favorecendo uma mudança de percepção em que é forçado a 'olhar o outro' e, ao mesmo tempo, a aspectos culturais que também o constituem.

$\mathrm{Na}$ academia, o debate sobre tais questões deve ser ampliado. A psicologia brasileira pode e deve ter um papel fundamental. Como sugeri em alguns momentos do trabalho, torna-se imprescindível o conhecimento de como os processos psicológicos se dão para a compreensão mais ampliada da problemática do afro-descendente, principalmente frente às armadilhas que um discurso social e político, como no caso de uma militância como modo de vida, pode provocar. Para isso devem ser desenvolvidos estudos que, se não diretamente voltados às questões do afrodescendente, pelo menos assumam como relevantes e incluam em seu bojo as variáveis etnoraciais, sem o risco de legitimar a discriminação.

Concluindo, creio ser importante que a pessoa branca deixe de negar suas raízes culturais africanas e indígenas, assim como o negro brasileiro, sua raízes culturais européias e também indígenas. Portanto, esta é uma luta do brasileiro, seja ele negro ou branco, é uma luta do brasileiro que é, culturalmente, 'negro $e$ branco $e$ índio', ou mais que isso, como diz Arnaldo Antunes em uma de suas canções ${ }^{4}$ :

"aqui somos mestiços mulatos cafuzos pardos mamelucos sararás crilouros guaranisseis e judárabes".

Como sugeri num ensaio anterior (Ferreira, 1999b), vivemos num mundo que só pode existir se o criarmos com o outro. Estamos aderidos uns aos outros. Nossos pontos de vista são sempre resultantes de vários enfoques que nos foram transmitidos por vários outros. Assim, a desafirmação da outra pessoa nos impede a convivência e, em decorrência, emperra-se o processo de desenvolvimento de um mundo mais humano, a construção de nossa própria 'morada' - uma grande construção coletiva, em que todos dependem uns dos outros. Assim, a aceitação da alteridade 
Psicologia \& Sociedade; 14 (1): 69-86; jan./jun.2002

não é uma escolha, mas uma condição ontológica para podermos existir como humanos e condição fundamental para que a reversão do preconceito possa se dar.

\section{REFERÊNCIAS BIBLIOGRÁFICAS}

ALVAREZ, H. F. Fundamentos de un modelo integrativo en psicoterapia. Buenos Aires, Paidós, 1992.

BAUMAN, Z. Modernidade e ambivalência. Rio de Janeiro, Jorge Zahar, 1999.

BERGER, P. L. \& LUCKMAN, T. The social construction of reality: a treatise in the sociology of knowledge. Harmondsworth, Penguin Books, 1972 .

CAMARGO, A. C. A experiência escolar na construção da identidade do brasileiro afro-descendente. São Paulo, 2001, 53 p. Relatório de Pesquisa - Universidade São Marcos.

CAVALLEIRO, E. S. Do silêncio do lar ao silêncio escolar: racismo, preconceito e discriminação na educação infantil. São Paulo, 1998. 144 p. Dissertação (Mestrado) - Faculdade de Educação, Universidade de São Paulo.

CIAMPA, A. C. A estória do Severino e a história da Severina: um ensaio de psicologia social. São Paulo, Brasiliense, 1987.

COELHO Jr., N. A identidade (em crise) do psicólogo. Cadernos de Subjetividade, 4, p. 302-314, 1996.

CONSORTE, J. G. A mestiçagem no Brasil: armadilhas e impasses. Margem, 10, dez., 107-117, 1999.

CROSS, W. E., Jr. Shades of black: diversity in African-American identity. Philadelphia, Temple University Press, 1991.

D'ADESKY, J. Pluralismo étnico e multiculturalismo: racismos e antiracismos no Brasil. São Paulo, 1996. 340 p. Tese (Doutorado) - Departamento de Antropologia Social da Faculdade de Filosofia, Letras e Ciênci- 
Ferreira, R.F. "O brasileiro, o racismo silencioso e a emancipação do afro-descendente"

as Humanas, Universidade de São Paulo.

D'ADESKY, J. Pluralismo étnico e multi-culturalismo: racismos e antiracismos no Brasil. Rio de Janeiro, Pallas, 2001.

FERREIRA, R. F. Uma história de lutas e vitórias: a construção da identidade de um afro-descendente brasileiro. São Paulo, 1999a. 281 p. Tese (Doutorado) - Instituto de Psicologia, Universidade de São Paulo.

FERREIRA, R. F. Verdade ou Solidariedade? A ciência, o conhecimento e a aceitação da alteridade. Eccos - Revista Científica, 1, 1, p. 9-24, 1999b.

FERREIRA, R. F. A construção da identidade do afro-descendente: a psicologia brasileira e a questão racial. In: BACELAR, J. \& CAROSO, C. org. Brasil: um país de negros? 2. ed. Rio de Janeiro, Pallas, 1999c, p. 71-86.

FERREIRA, R. F. Afro-descendente: identidade em construção. São Paulo, EDUC/ Rio de Janeiro, Pallas, 2000.

FERREIRA, R. F. Família e construção da identidade do brasileiro afrodescendente. São Paulo, 2002, 110 p. Relatório de Pesquisa - Universidade São Marcos.

FIGUEIREDO, L. C. M. Revisitando as psicologias: da epistemologia à ética das práticas e discursos psicológicos. São Paulo, EDUC / Petrópolis, RJ, Vozes, 1995.

HELMS, J. E. An overview of Black racial identity theory. In: HELMS, J. E. ed. Black and White racial identity: theory, research, and practice. Westport, Praeger, 1993. p. 9-32.

LARKIN NASCIMENTO, E. Sortilégio da Cor. São Paulo, 2000. 485 p. Tese (Doutorado) - Instituto de Psicologia, Universidade de São Paulo.

LÉVINAS, E. Entre nós: ensaios sobre a alteridade. Petrópolis, R.J., Vozes, 1997.

MIRANDA, M. G. O processo de socialização na escola: a evolução da condição social da criança. In: LANE, S. T. M. e CODO, W. org. Psicolo- 
Psicologia \& Sociedade; 14 (1): 69-86; jan./jun.2002

gia Social: o homem em movimento. 8. ed. São Paulo, Brasiliense, 1989, p. 125-135.

MORIN, E. Introdução ao pensamento complexo. 2. ed. Lisboa, Instituto Piaget, 1995.

MOURA, C. Sociologia do negro brasileiro. São Paulo, Ática, 1988.

NINA RODRIGUES, R. N. Os africanos no Brasil. 5. ed. São Paulo, Companhia Editora Nacional, 1977.

PARHAM, T. A.; HELMS, J. E. Relation of racial identity attitudes to selfactualization and affective states of black students. Journal of Counseling Psychology, 32, 3, p. 431-440, 1985.

PEREIRA, J. B. B. A criança negra: identidade étnica e socialização. $\mathrm{Ca}$ dernos de Pesquisa, 63, p. 41-45, 1987.

RODRIGUES, F. Racismo cordial. In Racismo cordial - Folha de São Paulo - Datafolha - A mais completa análise sobre o preconceito de cor no Brasil, 11-55. São Paulo, Ática, 1995.

SANTOS, B. S. Um discurso sobre as ciências. 8. ed. Porto, Edições Afrontamento, 1996.

SCHWARCZ, L. M. Usos e abusos da mestiçagem e da raça no Brasil: Uma história das teorias raciais em finais do século XIX. Afro-Ásia, 18, p. 77-101, 1996.

SCHWARCZ, L. K. M. (org.). História da vida privada no Brasil: contrastes da intimidade contemporânea. Vol. 4. São Paulo, Companhia das Letras, 1998.

SOUZA, N. S. Tornar-se negro ou as vicissitudes da identidade do negro brasileiro em ascensão social. 2. ed. Rio de Janeiro, Graal, 1983.

SOUZA, I. S. O resgate da identidade na travessia do movimento negro: arte, cultura e política. São Paulo, 1991. 376 p.Tese (Doutorado) - Instituto de Psicologia, Universidade de São Paulo. 
Ferreira, R.F. "O brasileiro, o racismo silencioso e

a emancipação do afro-descendente"

\title{
NOTAS
}

\begin{abstract}
${ }^{1}$ Assumo, neste ensaio, racismo como uma categoria que se refere a uma prática discriminatória institucionalizada, e alinhado com a posição de d'Adesky (1996), como uma prática de "desvalorização da identidade, opondo-se ao direito de cada indivíduo a viver segundo um enraizamento comunitário" (p. 91) e cuja consequiência principal, no campo político, é a fragilização das entidades comunitárias, cultural e etnicamente diferentes.

${ }^{2}$ Alinhado com D'Adesky (2001), considero que, do ponto de vista da genética, o conceito de raça é desprovido de valor científico e pouco operacional. Assim, neste ensaio, o termo 'raça' está sendo considerado como uma categoria construída socialmente e que é utilizada como referência para tipificar e classificar os indivíduos em função de suas características perceptíveis. Assim, tal categoria é de muita importância, pois torna-se referência para processos de discriminação e exclusão social em função de características fenotípicas visíveis.

${ }^{3}$ Cf. Larkin Nascimento (2000), "o termo eurocentrismo refere-se a essa imposição sobre os povos dominados de um universalismo hegemônico que define o mundo do ponto de vista do dominador" (p. 54).

${ }^{4}$ Trata-se da música "Inclassificáveis".
\end{abstract}

Ricardo Franklin Ferreira é Porofessor do Pós-Graduação em Psicologia da UNIMARCO. O endereço eletrônico do autor é: pospsicologia@smarcos.br

Ricardo Franklim Ferreira

$O$ brasileiro, o racismo silencioso e a identidade afro-descendente.

Recebido: $7 / 6 / 2002$

$1^{\text {a }}$ revisão: $30 / 7 / 2002$

Aceite final: $7 / 8 / 2002$ 